\title{
Chronic Maternal Hypertension
}

National Cancer Institute

\section{Source}

National Cancer Institute. Chronic Maternal Hypertension. NCI Thesaurus. Code

C112841.

Hypertension that predates pregnancy. 